\section{YOU ARE WHAT YOU EAT... AND DRINK}

Dr SIMON SAWHNEY discusses the implications of being on dialysis for your diet If $\begin{aligned} & \text { you spend an afternoon } \\ & \text { sitting in the waiting are }\end{aligned}$ sitting in the waiting area of
the Aberdeen dialysis unit, it will soon become clear that dialysis patients are obsessive about food an drink. There is constant animated discussion about what they can eat, whey are allowed to drink. to get by without breaking the rules. As a kidney specialist I confess that I am also obsessed with my patients consumption, and it can be difficult to Your home would be mo

unpleasant without regular tidy ups. Our kidneys are the housekeepers of the body. While you are reading this, blood from your body is passing toxic material and fluid drexcess toxic and turning into urine. As wing all housekeepers, they cope with all our mess and we hardly appreciate he scale of their work until they're

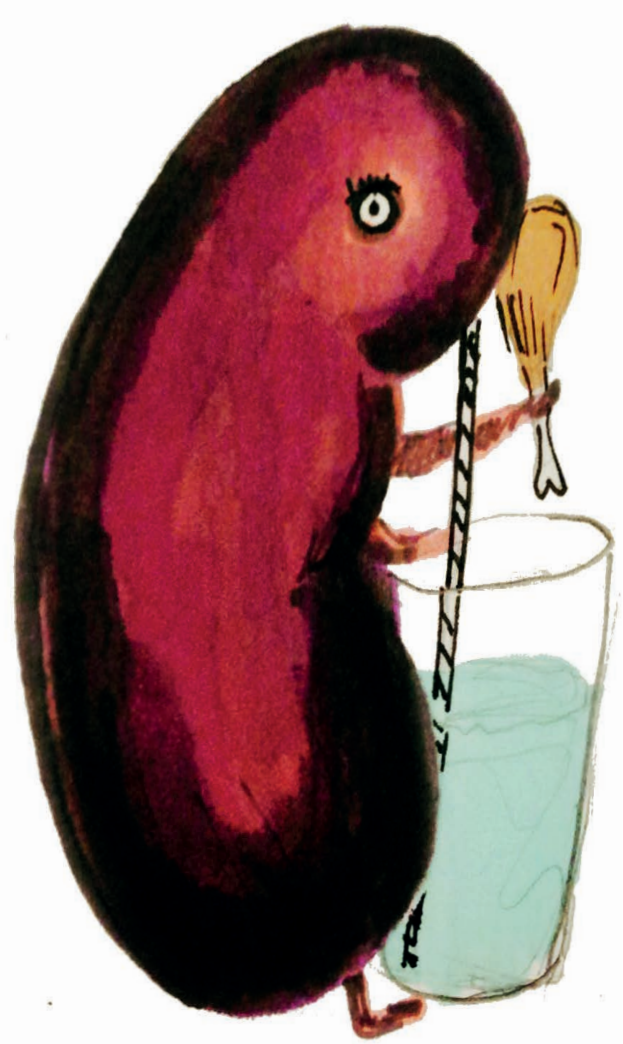

ILLUSTRATIONS: VANESSA DE MELLO
WE TAKE OUR KIDNEYS FOR GRANTED WHEN

WE OPEN THE FRIDGE OR DRINK A GLASS OF WATER. SUFFERERS OF KIDNEY DISEASE HAVE TO GO THROUGH HUGE UIFESTYLE CHANGES,

AND THE MORE WE

KNOW THE MORE WE CAN HELP

When the kidneys start to fail, too and laces a strain on the heart and ungs. It can even be fatal. We can help the failed kidneys by performin dialysis, a machine substitute for the tired organ. But while your kidneys dialysis only happens in short sessions. Dialysis patients therefore must manage their diet between sessions.

The most perceptible challenge is we often advise patients to stay well hydrated, but when you no longer make urine, the excess fluid will just build up. Patients can put on several kilos of fluid, which can be seen . dialysis. Every patient is different, but most must limit themselves to about a litre of fluid each day. They are also advised to cut down or avoid an almost endiess list of food chips, coffee, cereals, dried fruit and chocolate. This is not like a tempora compensation for an overindulgen Christmas. This is a diet for life, unless they are fortunate enough to
receive a transplant.
The kidneys can either stop
working suddenly or gradually, but dijusting to dialysis is particy, but difficult when it occurs out of the blue (known as "crash-landing"). Our patients get to know and help each other and you can often spot a seasoned dialysis attender offering ufferers are required to chang an much more than their diet. Patients have to plan their lives around thrice unexpected hospital stays why dialysis isn't working and deal with the complications that come from the strain of kidney disease on the rest of the body. The causes of kidney failur are diverse and we cannot preven Applied Renal Research Collaboration (ARRC) we are trying to do our bit. Aberdeen ARRC is led by Dr Corr Black and hosts one of the largest datasets for kidney disease in the we can prevent people from "crashlanding" on dialysis by finding ways to recognise sufferers early. A focus of our research is to predict which people may develop kidney failure kidney blood tests over time in the population. Our aim is to improve care in kidney disease by providing doctors and patients with the extra information they need to plan ahead. that's why we celebrate World Kidney Day to raise awareness of this essential organ. This year on March 12th you are all invited to participate in World Kidney Day by uploading a picture of yourself drinking a glass of or share it on the World Kidney Day Facebook page.

We take our kidneys for granted when we open the fridge or drink a glass of water. Sufterers of kidney lifestyle changes, and the more we know the more we can help.

DR SIMON SAWHNEY IS A NEPHROLOCIST AND PHD

\section{BEETLES FOR DINNER, WORMS FOR DESSERT}

\section{Ali Thomson ventures into the world of insect gastronom}

M/ en travelling abroad, on 1 of the inevitable culinary face is the opportunity to eat an insed of some description. This could be a plate of fire ants, a flambéed cricket, or even a scorpion lollipop! As much could be the norm in years to com, it Our global population continues to rise, and food shortages are becoming an increasingly prominent problem. Between urbanisation and a constant pressure to preserve rainforests an harder to increase arable land for food production.

IN GROUND CINNAMON, 800 FRAGMENTS OF INSECT IS CONSIDERED PERFECTLY

ACCEPTABLE, AS ARE TWO MAGGOTS OR 30 FLY EGGS IN A JAR OF PASTA SAUCE

Entomophagy (the consumption of insects as food) is one very problems. However in the shortage world the concept of eating insects is taboo. We spray our food with pesticides, and we've even based TV game shows around people eating inseds for a big deal? If you. Why is this such a big deal? If you step back that the rest of the world consider entomophagy to be completely unremarkable. In fact, insects are specifically eaten for their taste,

ARE THEY EVEN THAT NUTRITIONAL?

Yes! Insects are a fantastic source of protein. The nutritional value of

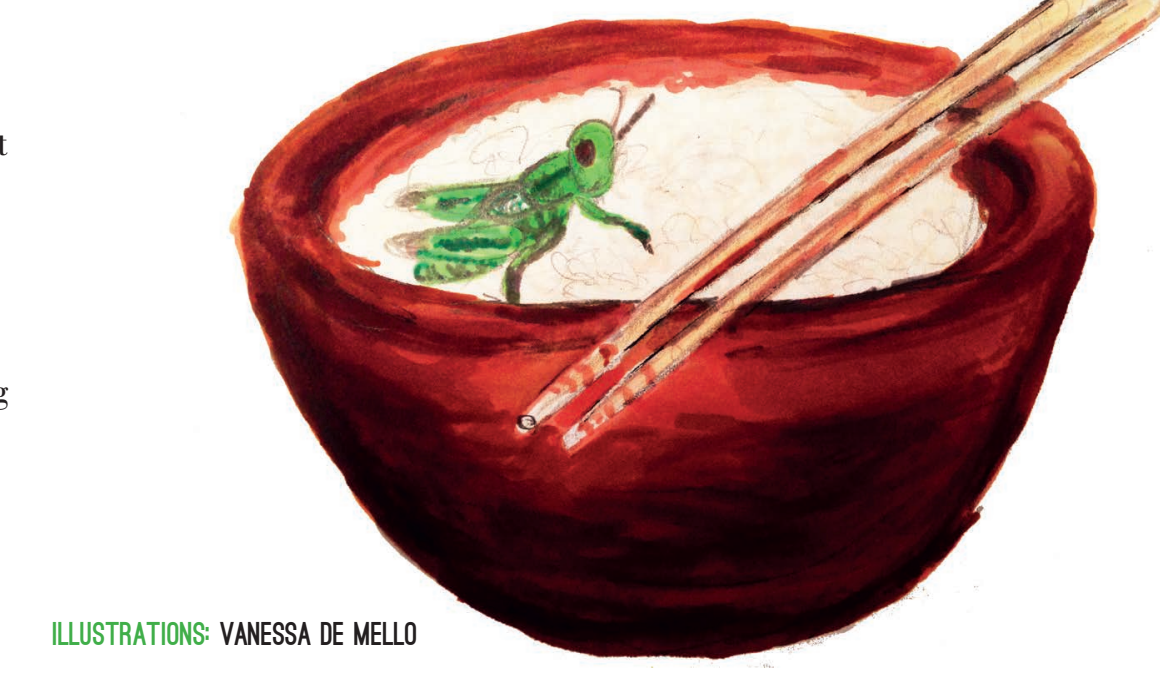

energy, protein and a whole host of
micronutrients. For instance, $100 \mathrm{~g}$ of locusts contains $499 \mathrm{kcal}$ and 100 1277 kcals - that's if you eat them raw, but feel free to prepare them in any way you wish.

BEEF VS INSECTS

Entomologist Dr Mark Finke from Arizona, Rio Verde looked at the

insects and compared them to that of beef. He concluded that beef has a higher content of micronutrients and amounts of amino acids, minerals far more efficient at turning food into body mass. Crickets can turn 1.7 Kgs of food into $1 \mathrm{Kg}$ of body mass, yet cows must eat a whopping $10 \mathrm{Kgs}$ y food in order to wan 1hy ar body eat $80 \%$ of a cricket, but onty, we of a cow. This makes insects a far superior food source, at least in term of efficiency.

We ve already begun eating insects. for some, we can't expect all of our food to be absolutely bug-free Insects are found on all food that is grown for human consumption. Delieve it or not, the US Food and Drug Administration has produced that appear in our food. In ground cinnamon, 800 fragments of insect is are two maggots or 30 fly eggs in a jar or pasta sauce.

CULINARY INSECT DELIGHTS

There are 1,417 species of edible insect, all prepared in a myriad o
ways. Crickets are a popular dryroasted snack, or eaten as a side with a bowl of rice. In South America the arantula is a popular dish. Peter says "If day-old chickens had no bones, had hair instead of feathers, and were the size of newborn sparrow, they might taste like

Witchetty grubs (moth larvae) are another favourite and a dietary staple
of the Aboriginal people of Australia. Eaten raw, they taste like almonds, but when cooked on hot coals they tastes like roast chicken.

WHAT CAN WE CONCLUDE?

Sprinkling dried grasshoppers on your corntlakes might not appeal to produce, full of nutrients, and when prepared in the right way they can taste delicious. Perhaps it's time to ditch the beerburger and embrace

ALL THONSON IS A PHD STUDENT IN MEDICAL SCIENCES fatty acids, but comparable or lower 